\title{
Cerámica y climatización saludable: paneles cerámicos radiantes en edificios. Condiciones de confort y demanda energética frente a sistemas convectivos
}

\section{Ceramics and healthy heating and cooling systems: thermal ceramic panels in buildings. Conditions of comfort and energy demand versus convective systems}

\author{
V. Echarri Iribarren $^{(*)}$, A. L. Galiano Garrigós ${ }^{(*)}$, Á. B. González Avilés ${ }^{(*)}$
}

\section{RESUMEN}

El gres porcelánico es un material ampliamente utilizado en edificación. En los últimos años su uso ha experimentado un nuevo espectro de líneas de innovación e invención en sus aplicaciones en la arquitectura. En esta investigación de analiza la patente Panel de Acondicionamiento Térmico Cerámico, consistente en piezas de gres porcelánico de bajo espesor, que contienen tramas capilares a base de tubos de polipropileno de 3,5 $\mathrm{mm}$ de diámetro, e interfaz de pasta conductora. Estos sistemas trabajan con agua fría o caliente produciendo una climatización saludable por superficies radiantes. Tras una primera experiencia de prototipado y colocación de paneles en pared en un despacho de oficina, se han realizado simulaciones en el Museo de la Universidad de Alicante, colocando los paneles en pared, techo o tipo bafle, previa monitorización del estado actual del edificio. Se han analizado los parámetros de comportamiento térmico y se han comparado con otros materiales de acabado habituales. Se han obtenido resultados de confort térmico y ahorros energéticos de forma comparativa frente a sistemas todo-aire.

Palabras clave: panel térmico cerámico; eficiencia energética; confort térmico; demanda energética.

\section{ABSTRACT}

Porcelain stoneware is a widely used building material. In recent years, its range of uses has expanded to encompass a new spectrum of innovative and inventive applications in architecture. In this research, we analysed the patented Thermal Ceramic Panel. This consists of a thin porcelain stoneware panel that incorporates a capillary system of polypropylene tubes measuring $3.5 \mathrm{~mm}$ in diameter embedded in a conductive ceramic interface. The system works with hot or cold water, producing healthy heating and cooling by means of radiant surfaces. Following an initial prototype test in which panels were placed on the walls of an office, we conducted simulations at the University of Alicante Museum using wall, ceiling and baffle panels, having previously monitored the state of the building. Thermal behaviour parameters were analysed and compared with those of other standard finishing materials, obtaining results for thermal comfort and energy savings in comparison with all-air systems.

Keywords: thermal ceramic panel; energy efficiency; thermal comfort; energy demand.

(*) Universidad de Alicante (España).

Persona de contacto/Corresponding author: Victor.Echarri@ua.es (V. Echarri Iribarren)

Cómo citar este artículo/Citation: Echarri Iribarren, V., Galiano Garrigós, A. L., González Avilés, Á. B. (2016). Cerámica y climatización saludable: paneles cerámicos radiantes en edificios. Condiciones de confort y demanda energética frente a sistemas convectivos. Informes de la Construcción, 68(544): e161, doi: http://dx.doi.org/10.3989/ic.15.160.m15.

Copyright: (C) 2016 CSIC. Licencia / License: Salvo indicación contraria, todos los contenidos de la edición electrónica de Informes de la Construcción se distribuyen bajo una licencia de uso y distribución Creative Commons Attribution License (CC BY) Spain 3.o. 
Los materiales cerámicos aplicados en los paramentos interiores de los edificios producen en el usuario una sensación térmica menos confortable que otros materiales de revestimiento y acabado. Su alto valor de efusividad y conductividad térmica frente a maderas, linóleos, enlucidos de yeso, etc., hace que los revestimientos roben más energía al usuario cuando se produce el contacto, y también por intercambio de energía radiante (véase Tabla 1). Son considerados materiales fríos y poco confortables, especialmente en régimen de invierno y en climatologías adversas.

Son numerosas las investigaciones que se han desarrollado para procurar sintetizar cerámica con un menor valor de conductividad térmica, pero en la mayoría de los casos sólo se ha podido conseguir aumentando la porosidad del material o su rugosidad, produciendo inconvenientes tanto en la resistencia mecánica como en la absorción de agua y suciedad. Las bondades del gres porcelánico - su absorción de agua por debajo del o,5\% y su resistencia mecánica (1)- hacen de él un material muy apreciado tanto para pavimentos como revestimientos en pared, y un material altamente competitivo para soluciones de fachada o cubierta, como los sistemas de colocación de fachada trasventilada (2). Si se procurara mejorar su comportamiento térmico al tacto, reduciendo su conductividad y efusividad térmica, perdería sus propiedades de inalterabilidad frente agentes externos y su alta resistencia mecánica.

Teniendo en cuenta estas dificultades en la síntesis de nuevos materiales cerámicos con mejor comportamiento térmico, recientemente se han realizado propuestas multicapa que pudieran presentar unos materiales cerámicos más confortables, pudiendo así competir con maderas naturales, maderas de alta densidad, linóleos, etc. Se han patentado soluciones de suelos radiantes mediante folio de hilo de cobre, y calentamiento por efecto joule (3). Se mejora la sensación de confort en el usuario y se consigue acondicionar en régimen de invierno, pero a costa de un excesivo coste de explotación y uso de energía, con mayores emisiones de $\mathrm{CO}_{2}$.

\section{SISTEMAS DE ACONDICIONAMIENTO POR SUPERFICIES RADIANTES CON TUBOS CAPILARES}

En los años 1980 se desarrollaron sistemas de acondicionamiento de espacios arquitectónicos a través de tramas capilares de tubos de polipropileno de $3 \mathrm{~mm}$ de diámetro aproximadamente, separados unos $10 \mathrm{~mm}$ entre sí. Estas tramas se pueden aplicar en cualquiera de los paramentos interiores -suelos, paredes, techos- mediante diversas técnicas de trasdosados, falsos techos, falsos muros o proyección de yeso. Se hace circular agua fría o caliente a través de dichas tramas, lográndose una climatización saludable, silenciosa y confortable, con contrastados ahorros energéticos frente a otros sistemas convencionales de climatización (4).

Estos sistemas acondicionan principalmente por radiación, y secundariamente por convección. Al trabajar enfriando o calentando moderadamente algunos paramentos, con una mínima deshumidificación en verano, y sin impulsión de aire frío o caliente, se consiguen muchos efectos positivos frente a los sistemas convectivos. El nivel sonoro disminuye drásticamente, el aire se mueve a velocidades de convección muy bajas y la temperatura del aire en verano es aproximadamente $2{ }^{\circ} \mathrm{C}$ superior a los sistemas convectivos. De esta forma el nivel de confort aumenta considerablemente. Además se producen importantes ahorros energéticos certificados por prestigiosos institutos de investigación. Los factores principales son la mayor capacidad de transporte energético del agua frente al aire, la autorregulación del sistema, y la reducción de cargas térmicas al estar en verano el aire interior a mayor temperatura (5).

Los esquemas de principio de aplicación de estos sistemas han sido ampliamente tratados en recientes publicaciones (6). Al trabajar con agua a temperaturas moderadas tanto en verano como en invierno, es factible el uso de energías alternativas: paneles solares, sistemas de acumulación de energía química a base de cloruro de litio (7), (8), sistemas de absorción, sistemas de energía geotérmica (9), o uso de agua de mar (10), entre otros (11).

\section{PANEL DE ACONDICIONAMIENTO TÉRMICO CERÁMICO (ATC)}

Los materiales de acabado en la aplicación de las tramas capilares son habitualmente paneles de cartón-yeso, bandejas metálicas de falso techo, yeso proyectado en paredes o techos y materiales habituales de pavimentación. Se han desarrollado también soluciones de hormigón fratasado con las tramas embebidas para pavimento, todas ellas con excelentes resultados. Hasta el momento no se había trabajado con gres porcelánico en paredes y techos, debido a las dificultades técnicas de ejecución, peso excesivo, dificultades de mantenimiento e inspección. Sin embargo, las nuevas piezas de gres porcelánico de gran formato han permitido

Tabla 1. Parámetros térmicos de posibles materiales de acabado con tramas capilares KaRo.

\begin{tabular}{|c|c|c|c|c|}
\hline Material & Densidad kg/m³ & $\begin{array}{c}\text { Calor específico } \\
\mathrm{J} /(\mathbf{k g} \cdot \mathbf{K})\end{array}$ & $\begin{array}{c}\text { Conductividad } \\
\mathrm{W} / \mathrm{m} \cdot \mathrm{K}\end{array}$ & $\begin{array}{c}\text { Efusividad } \\
\left(W \mathbf{s}^{1 / 2}\right) /\left(\mathrm{cm}^{2} \mathrm{~K}\right)\end{array}$ \\
\hline Acero (Me6) & 7.850 & 460 & $47-58$ & $1,30-1,45$ \\
\hline Aluminio (Me2) & 2.700 & 909 & $209-232$ & $2,26-2,39$ \\
\hline Cerámica gres (Ce ) & 2.300 & 836 & $0,8-1,3$ & $0,124-0,158$ \\
\hline Cerámica porcelánica (Ce ) & 2.350 & 921 & 0,81 & 0,1324 \\
\hline Linóleo (F1) & 535 & 1.400 & 0,081 & 0,055 \\
\hline Madera de haya (M2) & 800 & 1.340 & 0,143 & o,0392 \\
\hline Madera de roble & 850 & 2.386 & 0,209 & 0,0651 \\
\hline Vidrio (V1) & 2.700 & 833 & 0,81 & 0,1350 \\
\hline Yeso (R1) & 1.800 & 837 & 0,81 & 0,1104 \\
\hline Mármol (P1) & 2.400 & 879 & 2,09 & 0,2099 \\
\hline Cerámica porcelánica (Ce ) & 2.350 & 921 & $\mathbf{0 , 8 1}$ & 0,1324 \\
\hline
\end{tabular}


desarrollar paneles cerámicos prefabricados que incorporan las tramas (12).

Recientemente el grupo de investigación de la Universidad de Alicante «Tecnología y Sostenibilidad en Arquitectura», junto con ASCER y el ITC ha desarrollado un panel de acondicionamiento térmico cerámico ATC (13). Éste consiste en una o dos piezas de gres porcelánico de gran formato (14) y bajo espesor $-300 \times 100 \times 3 \mathrm{~mm}-$ armados con fibra de vidrio en una de sus caras, una trama capilar de tubos de polipropileno PPR de 3,5 mm de diámetro separados cada 10 $\mathrm{mm}$, y pasta conductora (15) para adherir el conjunto embebiendo la trama capilar (Figura 1). Es una solución idónea tanto para falsos techos cerámicos modulares, trasdosados en pared y techo de piezas de gran formato, o incluso en soluciones tipo bafle. Al trabajar con piezas de $3 \mathrm{~mm}$ en paneles prefabricados se consigue una gran facilidad de montaje en obra, mantenimiento y reposición en caso de fuga o avería.

Estos paneles de gres porcelánico y pasta conductora son idóneos para el correcto acondicionamiento térmico. En efecto, al estar dotados de conductividad térmica y efusividad altas, la capacidad térmica es similar a la de los habituales paneles de yeso (véase Tabla 2). Aunque en el caso de bandejas de techo metálico estos parámetros sean cuatro veces inferiores, los ensayos de tiempos mínimos realizados hasta alcanzar la potencia de emisión de proyecto, visualizados a través de termografías, son de unos diez minutos para el yeso y el gres porcelánico de bajo espesor, y de cinco minutos para el techo metálico. Se han realizado recientemente algunos prototipos que se han implantado en pared en un despacho de la Uni- versidad de Alicante, en un edificio todo-agua, en el que se han derivado las conexiones al fan-coil hacia la distribución a cuatro paneles radiantes de 2,5 × $1 \mathrm{~m}$ (véase Figura 2). Las condiciones de confort y tiempo y potencia de emisión están siendo satisfactorias.

Estos paneles cerámicos tienen además otras ventajas frente a los acabados en yeso y materiales metálicos, como la chapa de acero. Son inertes frente a las acciones químicas o procesos de oxidación y degradación por el uso. Su resistencia mecánica es también superior, pudiendo ser reforzada en su aplicación en pared, adhiriendo dos piezas cerámicas mediante un butiral con un $3+3 \mathrm{~mm}$. No requiere mantenimiento alguno, y su sustitución es sencilla. Para el caso de falsos techos el gres porcelánico de bajo espesor es ligero y no sufre deformaciones o desperfectos en las operaciones de mantenimiento. Sus posibilidades estéticas son enormes, con multitud de efectos de acabado, pudiéndose incluso reproducir imágenes a través de la técnica inkjet (16), (17) con anterioridad al proceso de cocción.

\section{APLICACIÓN INICIAL DE LOS PANELES ATC EN EL MUSEO DE LA UNIVERSIDAD DE ALICANTE (MUA)}

El Museo de la Universidad de Alicante es un volumen flexible de $63 \times 22,5 \times 9$ metros en su interior. Se configura a base de unas nayas en todo su perímetro que permiten la circulación en tres niveles para tareas de mantenimiento. La circulación bajo cubierta se realiza también a través de 8 costillas. Este espacio buffer aloja todas las instalaciones de iluminación, climatización y evacuación de aguas del edificio (Figura 4). La

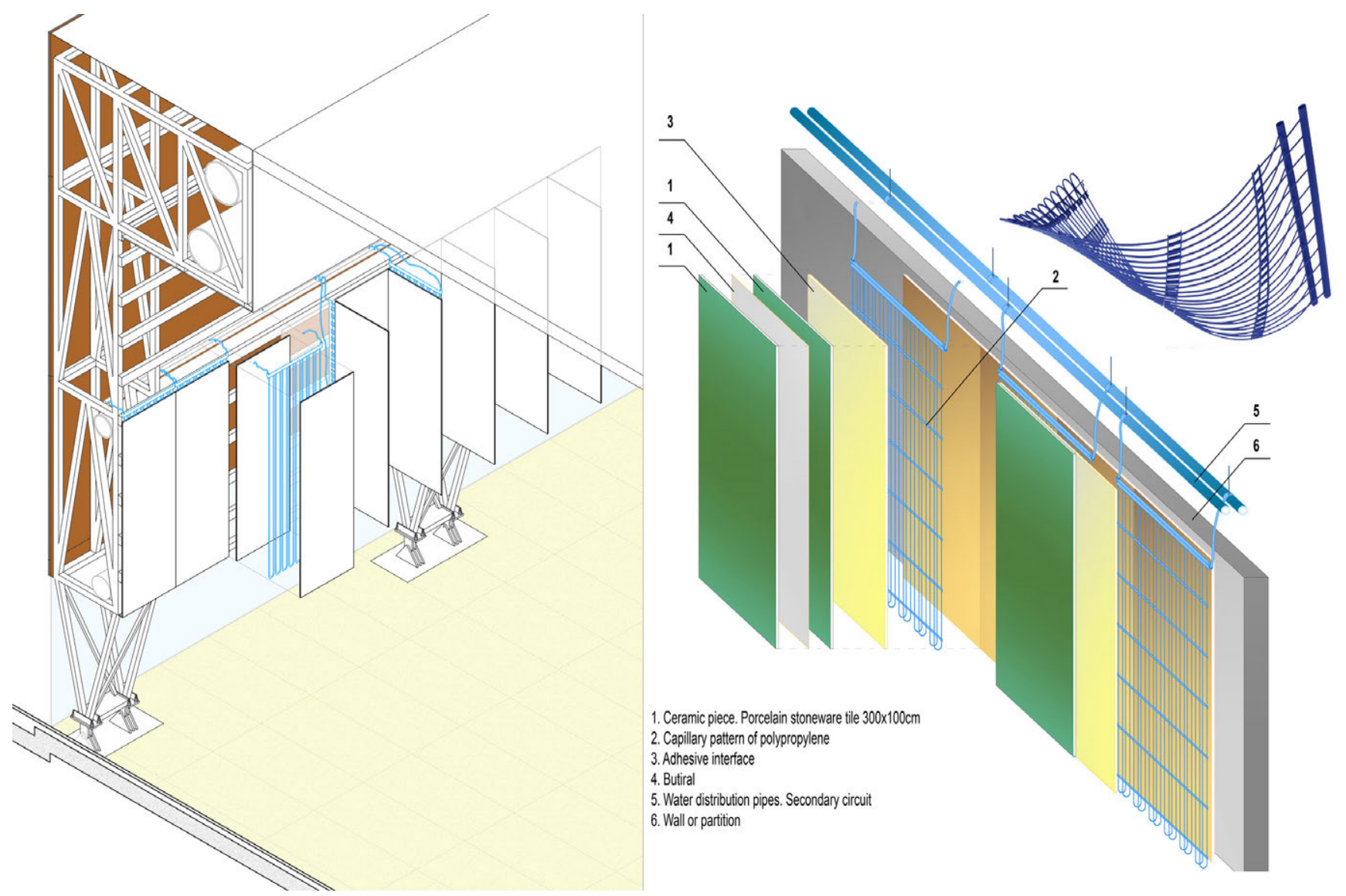

Figura. 1. Patente de referencia P201001626. Panel de Acondicionamiento Térmico Cerámico aplicado en el MUA. 
Tabla 2. Comparativa de capacidad térmica de materiales de acabado con tramas capilares KaRo.

\begin{tabular}{|c|c|c|c|c|c|}
\hline Material & $\begin{array}{c}\text { Calor específico } \\
\text { KJ/kg K }\end{array}$ & $\begin{array}{c}\text { Peso específico } \\
\mathrm{kg} / \mathbf{m}^{3}\end{array}$ & $\begin{array}{c}\text { Peso } \\
\mathrm{kg} / \mathrm{m}^{2}\end{array}$ & $\begin{array}{c}\text { Capacidad térmica } \\
\mathrm{Wh} / \mathbf{m}^{2}\end{array}$ & $\begin{array}{l}\text { Capacidad } \\
\text { térmica \% }\end{array}$ \\
\hline Techo metálico & 0,48 & 7800 & 5,46 & 5,9 & 62 \\
\hline Agua & 4,18 & 1000 & 0,285 & 2,7 & 28 \\
\hline Polipropileno & 1,5 & 980 & 0,28 & 0,9 & 10 \\
\hline SUMA & & & & 9,5 & 100 \\
\hline Yeso & 1,09 & 1000 & 10,00 & 36,6 & 87 \\
\hline Agua & 4,18 & 1000 & 0,285 & 2,7 & 10 \\
\hline Polipropileno & 1,5 & 980 & 0,28 & 0,9 & 3 \\
\hline SUMA & & & & 40,0 & 100 \\
\hline Cerámica gres & 0,836 & 2300 & 20,7 & 38,45 & 91,4 \\
\hline Agua & 4,18 & 1000 & 0,285 & 2,7 & 6,4 \\
\hline Polipropileno & 1,5 & 980 & 0,28 & 0,9 & 2,2 \\
\hline SUMA & & & & 42,06 & 100 \\
\hline Gres porcelánico $3+3$ & 0,921 & 2350 & 14,1 & 28,85 & 73,3 \\
\hline Pasta conductora & 0,75 & 830 & 4,15 & 6,9 & 17,5 \\
\hline Agua & 4,18 & 1000 & 0,285 & 2,7 & 6,8 \\
\hline Polipropileno & 1,5 & 980 & 0,28 & 0,9 & 2,4 \\
\hline SUMA & & & & $\mathbf{3 9 , 3 6}$ & 100 \\
\hline
\end{tabular}

cubierta contiene 7 enormes lucernarios con lamas exteriores orientables de aluminio. El perímetro en planta baja es de vidrio simple, con protección a base de paneles DM.

La envolvente interior está formada por paneles DM lacados en blanco pegados con cordón de poliuretano sobre bastidores de madera, atornillados éstos sobre subestructura de tubo de acero. La envolvente exterior estaba formada por paneles tipo sándwich con aislamiento de lana de roca, panel exte- rior fenólico, panel interior DM y bastidores de madera en su perímetro. Dicha envolvente sufrió lesiones debidas a la humedad, la radiación solar y el diferencial térmico debido a los puentes térmicos generados por la discontinuidad del material de aislamiento (18). En 2010 la envolvente fue rehabilitada. Se aplicaron sobre la piel existente $3 \mathrm{~cm}$ de poliuretano proyectado, y se generó una fachada ventilada, aprovechando la subestructura metálica existente, con paneles fenólicos de última generación (Figura 4).

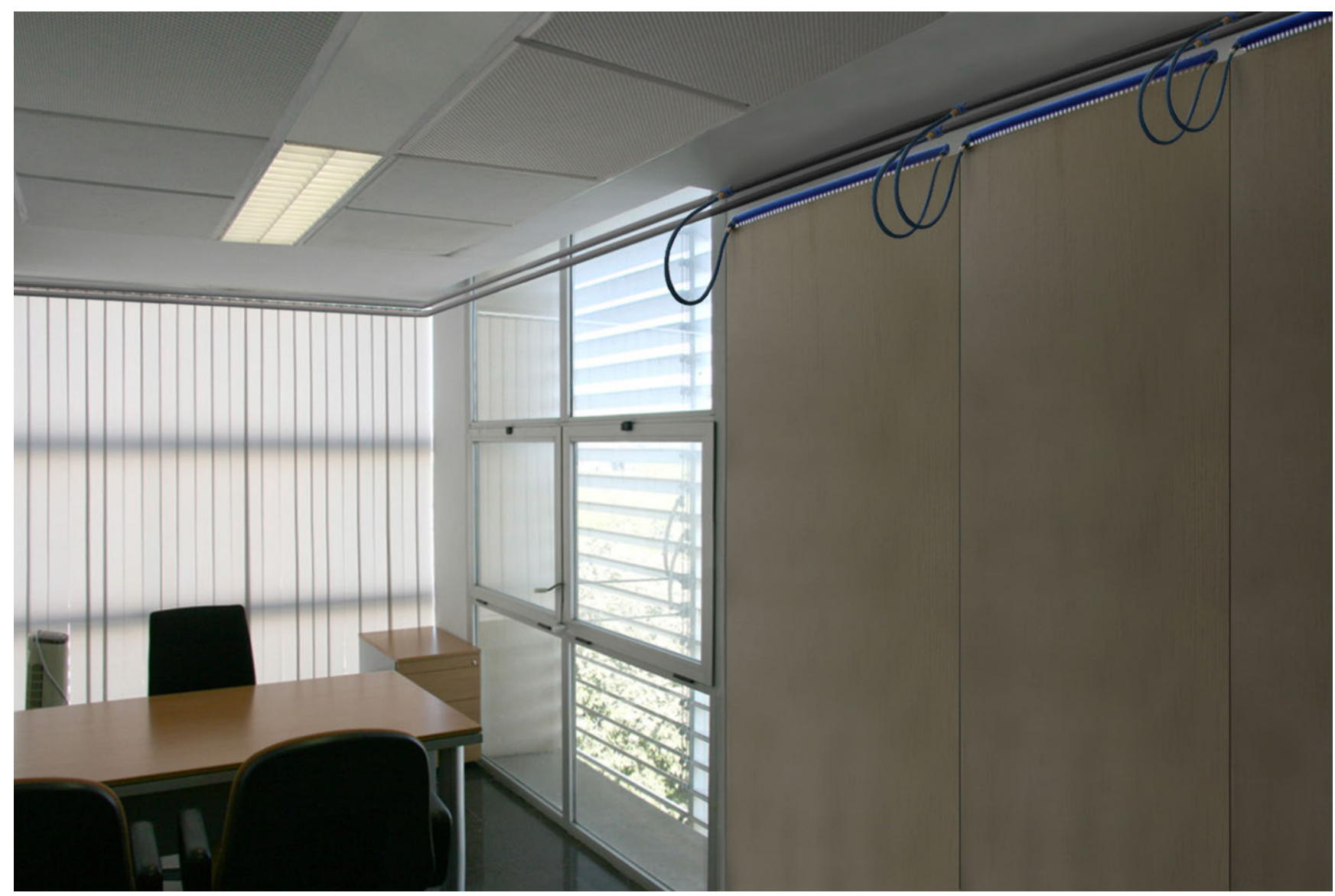

Figura. 2. Aplicación de los paneles térmicos cerámicos ATC en despacho. 
En una primera investigación se monitorizó el edificio en 2013 durante las semanas características para verano (3-9 de agosto) e invierno (17-23 de febrero) que define el programa Design Builder para el fichero climático de Alicante. A través del software Design Builder se procedió a realizar simulaciones de comportamiento térmico y cálculo de demandas energéticas, tanto en estado actual como antes de la reforma de la envolvente. También se simuló la aplicación en pared de los paneles cerámicos térmicos antes descritos, en el interior del espacio principal del MUA, en sustitución de los paneles de DM existentes.

Los resultados se publicaron en 2014 (19). La incidencia del nuevo aislamiento y la reducción de los puentes térmicos, resueltos de manera satisfactoria con la nueva envolvente generada, redujeron en un 12 y un 6\%, respectivamente, la demanda energética. Se obtuvieron resultados de demanda energética con temperaturas operativas de consigna de $20{ }^{\circ} \mathrm{C}$ en invierno y $24{ }^{\circ} \mathrm{C}$ en verano, ocupación de 0,15 personas/ $\mathrm{m}^{2}$ y aire de ventilación de $1 \mathrm{ren} / \mathrm{h}$. Se comparó además la aplicación de los paneles térmicos cerámicos en pared frente al sistema de climatización existente todo-aire. Los resultados de confort térmico en régimen de verano fueron igualmente satisfactorios para el usuario, siendo el sistema radiante igualmente capaz de disipar en régimen de verano, por convección y radiación, en torno a 6o W de energía por metro cuadrado de superficie corporal.

\section{ANÁLISIS COMPARATIVO DE LAS DIVERSAS APLICACIONES DE LOS PANELES CERÁMICOS}

Tras estos primeros resultados de aplicación de los paneles ATC en el MUA se propone una investigación más amplia con un análisis comparativo de algunas de las diversas formas de aplicación. En la Tabla 3 se exponen las 5 opciones viables de colocación (opciones 2 a 6): en paredes opuestas con superficie continua, en techo continuo descolgado, paneles verticales en techo tipo bafle y paneles en pared ortogonales al paramento. Los paneles de gres porcelánico blanco alterarían el aspecto estético en la mayor parte de las opciones presentadas. Sin embargo, permitirían la entrada de luz natural de modo similar al actual. Únicamente en la opción 6 habría una variación del efecto de entrada de luz al disponerse ortogonalmente al vidrio perimetral de planta baja.

En esta segunda investigación se procedió a ampliar el rango de monitorización hasta el ciclo completo del año 2014, con más de 30 sensores (Figura 5). El edificio se monitorizó con sensores de temperatura, humedad relativa, piranómetro, etc., tanto en la sala principal anteriormente descrita, como en el resto de salas ubicadas bajo el estanque (véase Figura 3). El sistema de monitorización se diseñó mediante sistema wireless. Sensores de temperatura se conectan a pequeños analizadores modelo «EL-WiFi-TC. Thermocouple Probe Data logger». Analizadores «EL-WiFi-TH, Temperature and humidity data logger», con sensores incorporados de temperatura y humedad relativa, interpretan los datos registrados y envían señales wifi a un router modelo «RouterOS», conectado a un ordenador portátil (Figuras 6 y 7). Mediante instalación del software «EasyLog WiFi Software» se reciben los datos y se almacenan en el ordenador. A continuación los datos se envían diariamente a un disco virtual. A través de un código personalizado se puede acceder a dicha información desde cualquier ordenador a través de la red. Además se instaló una pequeña estación con sensores de temperatura del aire exterior, humedad relativa y piranómetro de medición de radiación solar. De forma paralela se obtuvieron los datos climatológicos registrados por la estación meteorológica del Laboratorio Climatológico de la Universidad de Alicante.

Para realizar las simulaciones de comportamiento del edificio en términos de demanda energética y parámetros de confort interior se introdujeron en la herramienta Design Builder los siguientes datos. El periodo de invierno cubre del 1 de diciembre al 30 de abril y el de verano del 1 de mayo al 30 de noviembre. Es el protocolo establecido por la UA, ajustado a las condiciones climáticas habituales en San Vicente del Raspeig. El horario de funcionamiento es de 9:00 a 20:00 h. Las temperaturas de consigna del aire interior son de $20{ }^{\circ} \mathrm{C}$ en invierno y $24{ }^{\circ} \mathrm{C}$ en verano. La ocupación, para el cálculo normativo de renovación de aire, es de 709 personas, 0,5 personas por $\mathrm{m}^{2}$. Se deben renovar 12,5 litros por segundo y persona, lo que equivale a $2,5 \mathrm{ren} / \mathrm{h}$. La infiltración del aire a través de la envolvente es moderada gracias a la aplicación de espuma de poliuretano en la reforma de los paneles fenólicos

Tabla 3. Definición de las distintas opciones de colocación de los paneles térmicos cerámicos.

\begin{tabular}{|l|l|}
\hline $\begin{array}{l}\text { OPCIÓN 1. } \\
\text { Estado actual. Sin } \\
\text { paneles radiantes, con } \\
\text { el sistema de impulsión } \\
\text { todo-aire que existe } \\
\text { actualmente. }\end{array}$ \\
\hline $\begin{array}{l}\text { OPCIÓN 3. } \\
\text { Paneles cerámicos } \\
\text { radiantes colocados } \\
\text { forrando el techo, a modo } \\
\text { de trasdosado. }\end{array}$ \\
$\begin{array}{l}\text { OPCIÓN 5. } \\
\text { Paneles colocados } \\
\text { colgando del techo tipo } \\
\text { bafle. Separación de } \\
\text { paneles cada 1 m. }\end{array}$
\end{tabular}




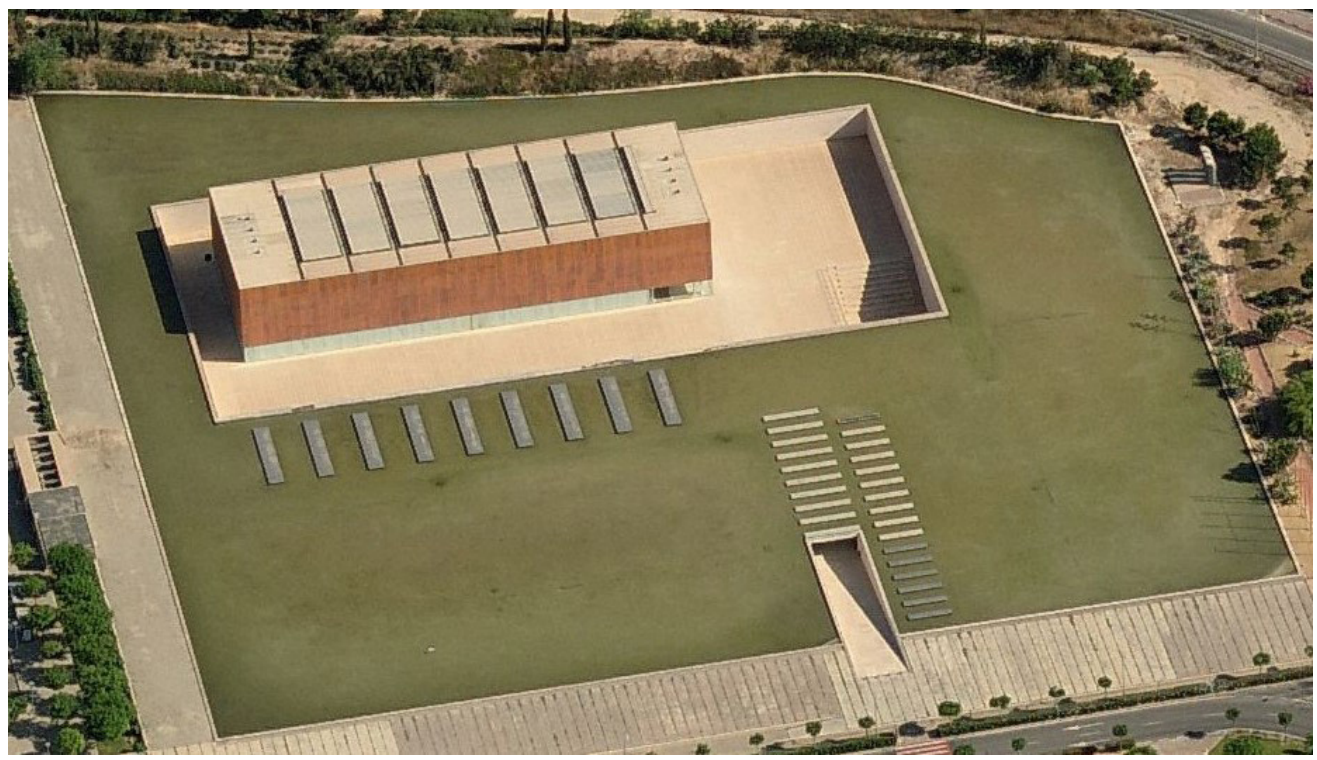

Figura. 3. Vista aérea del Museo de la Universidad de Alicante (MUA). Fuente: Bing Maps.

(18). Se ha considerado en inicio de $0,7 \mathrm{ren} / \mathrm{h}$, y se ha ajustado posteriormente en la fase de calibración. La iluminación tiene una potencia de 4,82 kW. Los lucernarios, de grandes dimensiones, se han considerado con las lamas de aluminio interiores completamente cerradas al paso de la radiación solar, en su estado habitual. El vidrio perimetral de planta baja se protege con paneles continuos de madera DM a una separación de 1,40 m, que impiden la radiación solar directa en el interior.

Para ajustar los parámetros obtenidos por simulación a los datos reales, o calibrar el modelo, se realizaron mediciones de transmitancias térmicas en las cuatro fachadas del edificio, en las pieles interiores de DM que separan las nayas del espacio de exposición, en el vidrio simple perimetral de la planta baja y la cubierta. Los valores fueron coincidentes con los obtenidos con Design Builder tras una leve corrección del espesor medio del aislamiento de espuma de poliuterano aplicado por proyección en la reforma de la fachada (18). Se calcularon valores de puentes térmicos a través del programa Antherm y se introdujeron en la modelización. Por último se ajustaron los valores de ocupación real de personas, fichero climático obtenido in situ corregido con valores de los datos climatológicos registrados por la estación meteorológica del Laboratorio Climatológico de la Universidad de Alicante, e infiltración de aire, para ajustar la demanda energética anual obtenida frente a consumos energéticos reales proporcionados por el Vicerrectorado de Campus y Sostenibilidad de la Universidad de Alicante. Éstos son de 197,5 MWh/a para la climatización todo-aire existente. Se hizo lo mismo para ajustar las temperaturas superficiales interiores y la temperatura del aire interior. Es preciso indicar que el hecho de que el usuario no tiene acceso a cambios personalizados en la climatización, y que se tengan temperaturas de consigna fijas
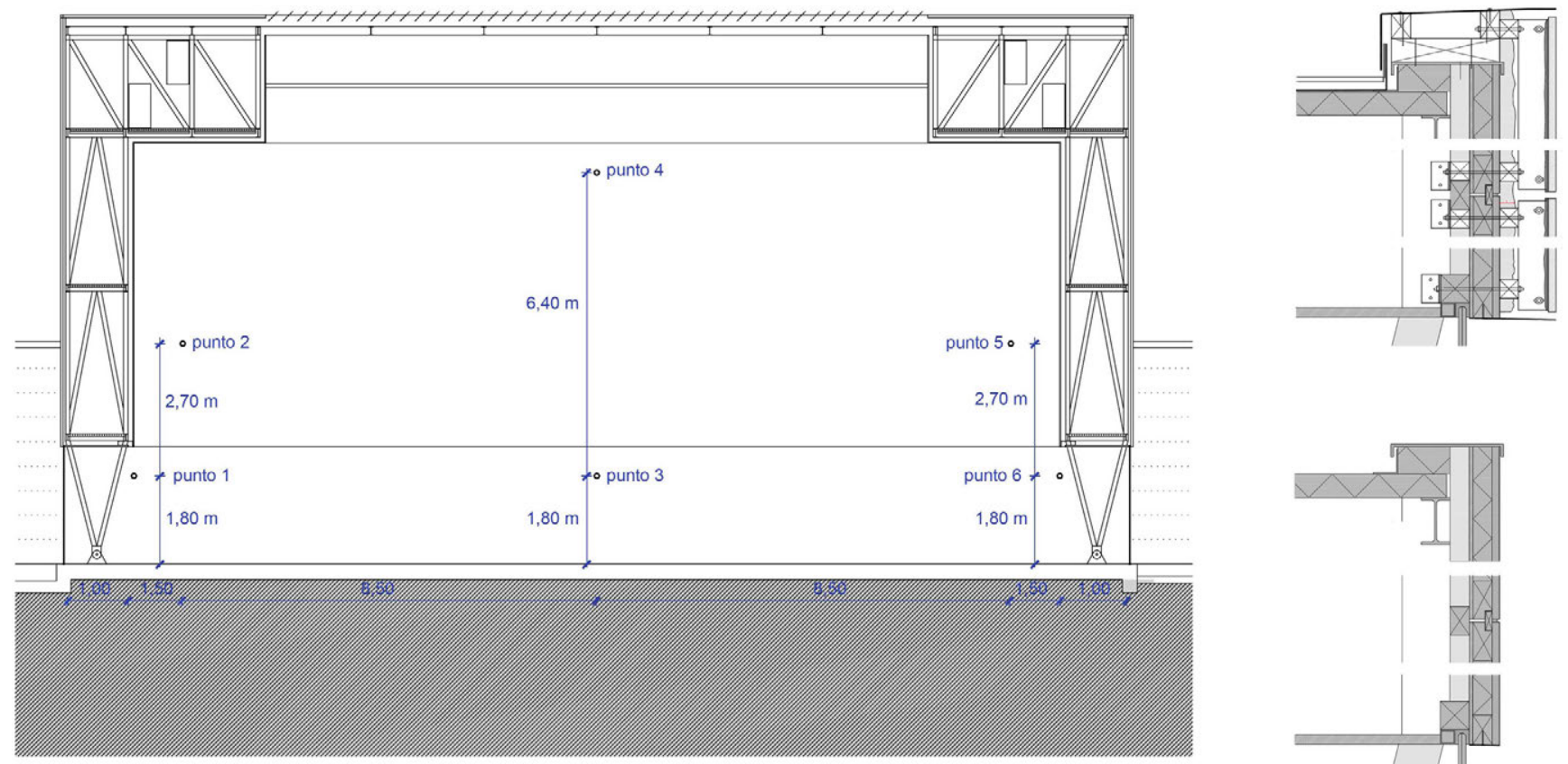

Figura 4. Sección transversal del MUA. Detalle constructivo de la fachada ventilada. 


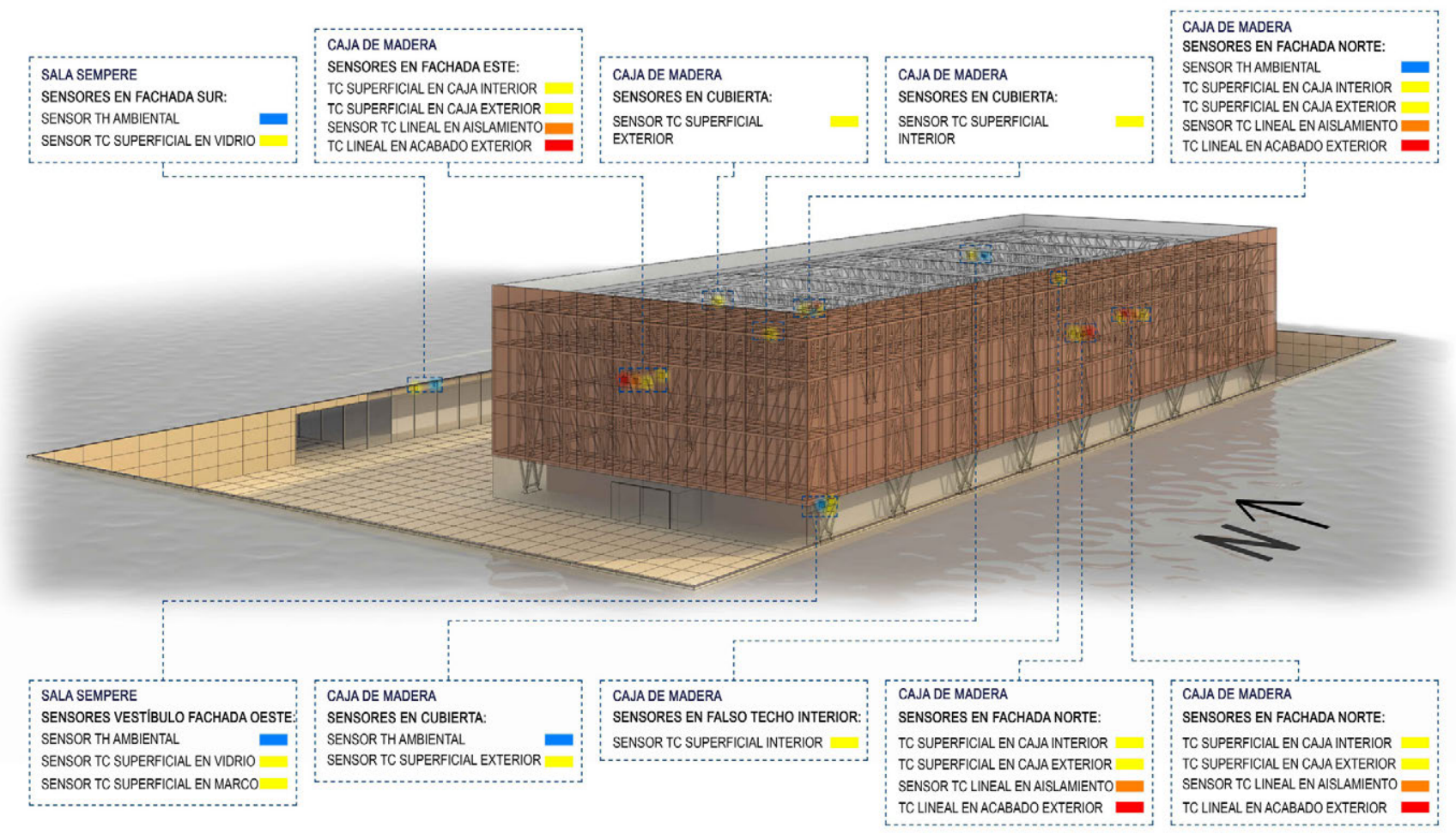

Figura 5. Monitorización del MUA. Ubicación de sensores.

de $20^{\circ} \mathrm{C}$ en invierno y $24{ }^{\circ} \mathrm{C}$ en verano desde las 9:00 a las 20:00 h facilitó el proceso de calibración.

En esta investigación se realizará un análisis comparativo de la capacidad de los distintos sistemas de climatización aplica- dos en el MUA. La sensación térmica del usuario dependerá del intercambio de calor por convección y radiación con las superficies y objetos del entorno, de la capacidad de emisión de vapor de agua al aire interior a través de la piel por transpiración y por la respiración, así como de la calidad del
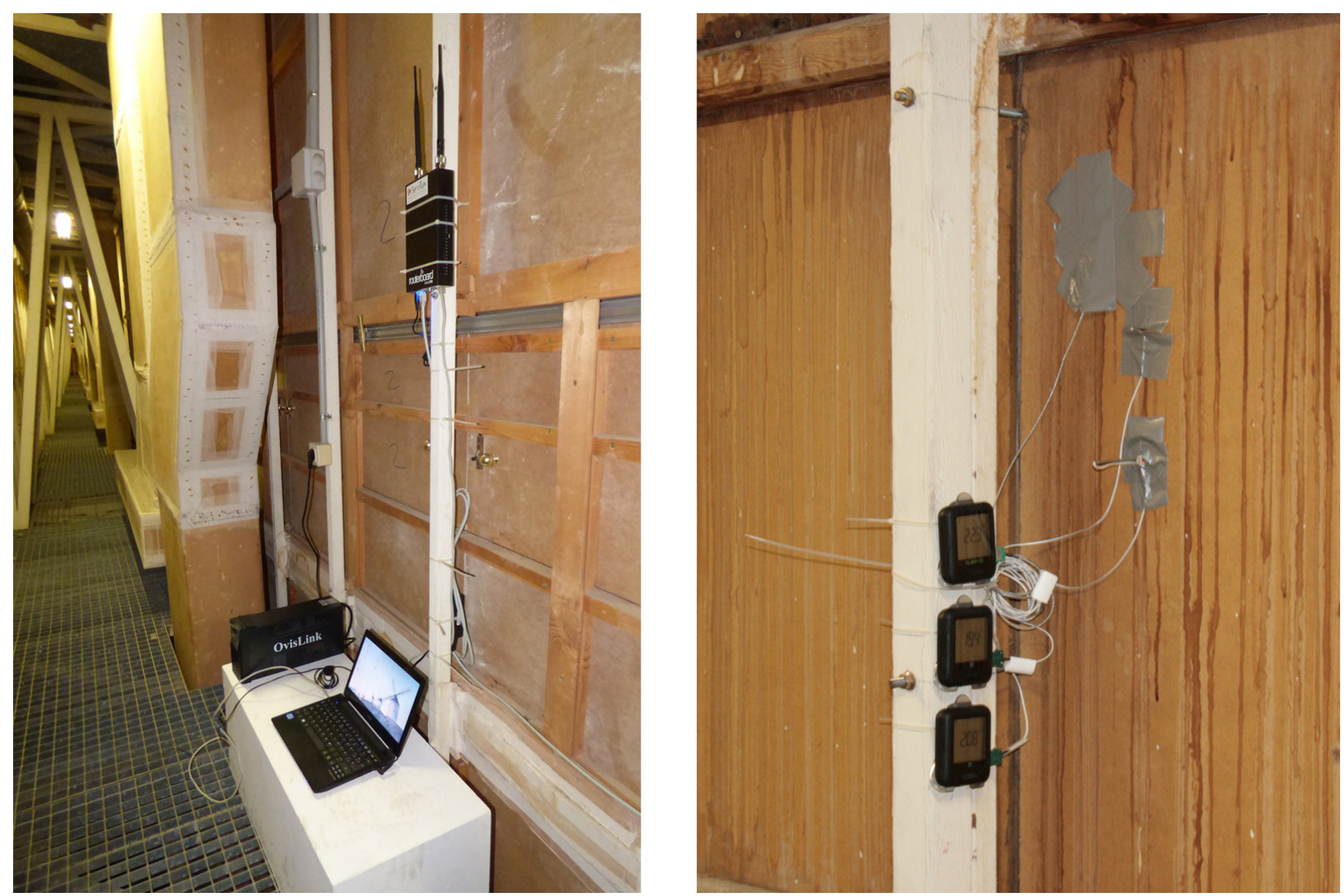

Figura 6. Monitorización del MUA. Sistema wireless: router, portátil, analizadores y sensores. 

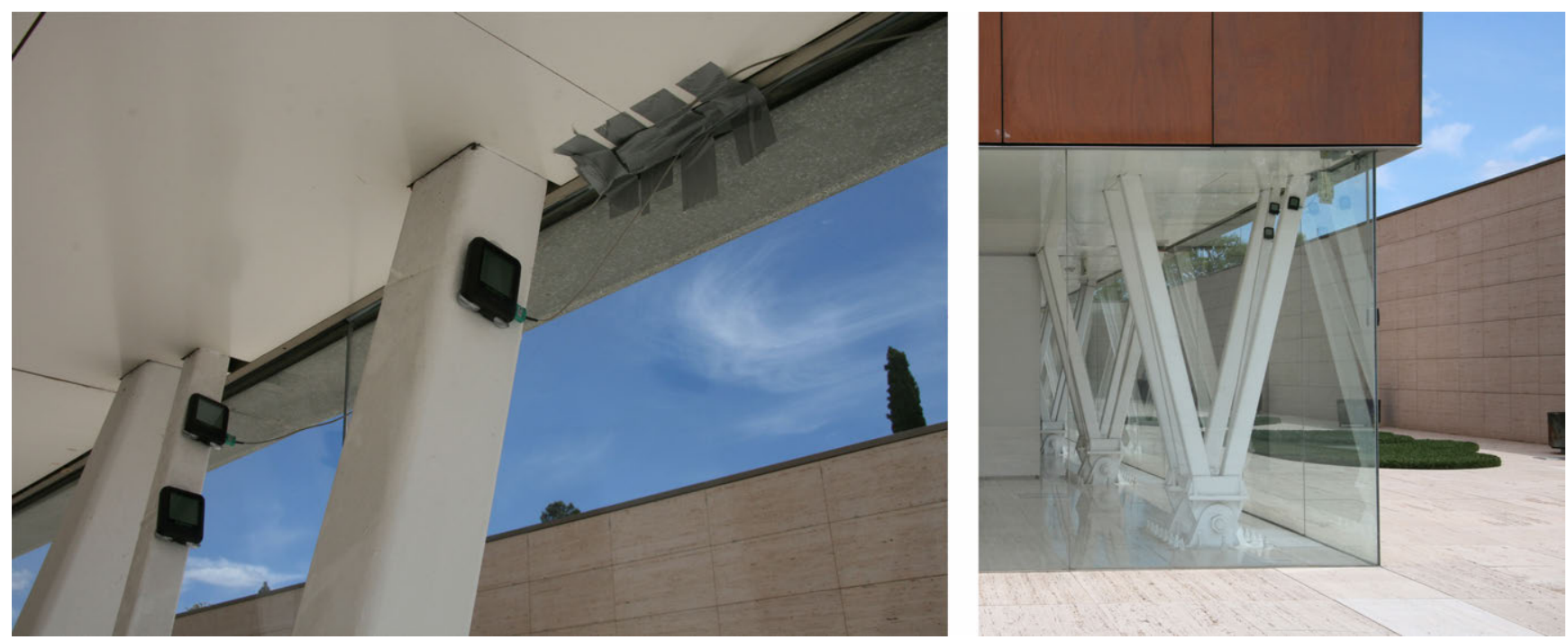

Figura 7. Monitorización del MUA. Sistema wireless: analizadores y sensores en planta baja.

aire interior. Se obtendrán además los valores de temperatura operativa para cada una de las opciones y se relacionarán con las exigencias normativas en este terreno. Por último se procederá, a través de la herramienta de simulación Design Builder, a obtener los valores de demanda energética en los distintos escenarios, y así evaluar la capacidad de los sistemas térmicos radiantes para reducir dicha demanda.

\subsection{Evaluación comparativa de la sensación térmica del usuario}

Para evaluar la sensación térmica del usuario se seguirá el protocolo definido por Fanger (20), adaptado con nuevas formulaciones ajustadas a algunos espacios arquitectónicos (21). Para que un individuo se encuentre con sensación de bienestar en un local es necesario analizar cuidadosamente todos aquellos parámetros que lo determinan de modo directo, principalmente la temperatura seca del aire, su humedad relativa, la velocidad del aire que lo envuelve y la temperatura superficial de cada uno de los paramentos que configuran dicho local. Otros parámetros inciden de forma indirecta, como la pureza del aire envolvente o el nivel sonoro. El individuo necesita mantener una temperatura corporal prácticamente constante entre 36,5 y $37^{\circ} \mathrm{C}$. Para la sensación de confort requiere del mantenimiento del balance energético según la expresión:

$$
\sum q=q_{m e t}-q_{e v} \pm q_{c i} \pm q_{c v i} \pm q_{r d i}=\mathrm{o}
$$

La determinación de las condiciones ideales de temperatura y humedad relativa que garanticen las actividades habituales de los individuos en espacios interiores es una tarea compleja, que ha motivado numerosas investigaciones (22), (23). Las pérdidas de calor por convección se obtienen a través de la expresión:

$$
q_{c v i}=h_{c}\left(T_{i}-T_{a}\right) \quad\left(\mathrm{W} / \mathrm{m}^{2}\right)
$$

El factor de convección $h_{c}$ está directamente relacionado con la velocidad del aire y la posición en que se encuentre el individuo. Habitualmente dicho factor tiene un valor medio de $3,5 \mathrm{~W} / \mathrm{m}^{2}{ }^{\circ} \mathrm{C}$, con una velocidad del aire de $0,1 \mathrm{~m} / \mathrm{s}, \mathrm{y} 4,5 \mathrm{~W} /$ $\mathrm{m}^{2}{ }^{\circ} \mathrm{C}$, con una velocidad del aire de $0,2 \mathrm{~m} / \mathrm{s}$. Se puede obtener su valor a través de la expresión:

$$
h_{c}=8,3 \cdot v^{0,24}\left(\mathrm{~W} / \mathrm{m}^{2} \mathrm{C}\right)
$$

Dado que el valor medio de la superficie corporal es de $1,7 \mathrm{~m}^{2}$ (24), la expresión [3] podría simplificarse para el cálculo total de las pérdidas por convección del ser humano:

$$
h_{c}=14,11 \cdot v^{0,24}\left(\mathrm{~W} /{ }^{\circ} \mathrm{C}\right)
$$

La obtención del valor de pérdidas por radiación es tarea más compleja. Se basa en la ley de Stefan-Boltzman, en función de las cuartas potencias de las temperaturas superficiales del individuo y de las paredes que configuran el local. Al trabajar con planos finitos, en diversas posiciones respecto del individuo, la determinación de la transferencia de calor por radiación se hace extremadamente compleja. Fanger llevó a cabo una cuantificación de los factores forma que inciden en la determinación del valor real de la temperatura radiante media de los paramentos (20). La expresión del cálculo de $T_{r m}$ se puede simplificar según la expresión recogida en su manual:

$$
T_{m r t}=T_{1} \cdot F_{P-1}+T_{2} \cdot F_{P-2}+\cdots+T_{N} \cdot F_{P-N}
$$

A través de la temperatura radiante media así obtenida y del valor de la temperatura de la piel y/o la ropa del individuo, de forma experimental se puede obtener el valor de la transferencia de calor por radiación, sabiendo que el coeficiente de pérdidas por radiación $h_{r}$ adopta valores aproximados de $4,7 \mathrm{~W} / \mathrm{m}^{20} \mathrm{C}$ con temperatura estimable del cuerpo humano $T_{i}$ de $30^{\circ} \mathrm{C}$.

$$
q_{r d i}=h_{r}\left(T_{i}-T_{r m}\right) \quad\left(\mathrm{W} / \mathrm{m}^{2}\right)
$$

Para proceder a la evaluación de las pérdidas de calor sensible por radiación y convección del individuo, en la sala del MUA se obtuvieron datos de temperaturas superficiales por monitorización del estado actual u OP 1, con sistema convectivo, y los datos homólogos para las opciones radiantes a través de simulaciones con Design Builder. Con estos presupuestos se procedió a calcular los factores forma según el método de Fanger para las 6 opciones, con la posición de individuo en pie y en el centro de la sala, y posteriormente las temperaturas radiantes medias según la expresión [5]. Los resultados se muestran en la Tabla 4. 
Igualmente se obtuvieron valores de velocidad del aire interior en el centro de la sala, inicialmente por a través de sensores Testo, y posteriormente en los sistemas radiantes mediante simulación. Una vez conocidos los valores de temperatura radiante media, temperatura del aire interior y velocidad del aire envolvente al individuo en el centro de la sala se cuantificaron los valores $q_{r d i}$ y $q_{c v i}$ de pérdidas de calor por radiación y convección para un individuo, para cada uno de los escenarios analizados. Los resultados se muestran en la Tabla 5. Se puede comprobar cómo las diferencias cuantitativas de la suma de ambos valores son muy similares en sistemas convectivos frente a sistemas radiantes.

Podemos concluir que, dado que los valores habituales de emisión de calor sensible del usuario andando lentamente son $90 \mathrm{~W}$ (22), las opciones que dan mejores resultados son OP 1, OP 3 y OP 5. La aplicación de los paneles radiantes en techo, para régimen de verano, favorecen la convección del aire, y por tanto aumenta su capacidad de emisión y la velocidad del aire en la zona de ocupación. En las opciones de colocación de los paneles radiantes en pared la capacidad de cesión de calor sensible del individuo disminuye a valores inferiores a los $90 \mathrm{~W}$ necesarios. Consecuentemente se debería aumentar la potencia de emisión de los paneles cerámicos radiantes bajando la temperatura superficial. Si se disminuyera ésta de 17 a $16^{\circ} \mathrm{C}$, aumentarían las pérdidas de individuo por radiación a valores de $45 \mathrm{~W}$, y también por convección al aumentar la velocidad del aire a valores en torno a $35 \mathrm{~W}$, acercándonos así a los valores de confort.

No se han tenido en cuenta para el análisis comparativo las emisiones de calor latente, que para el individuo en las condiciones antes señaladas suponen un valor aproximado de 70 W. Los equipos de bomba de calor en la opción 1 y los fan-coils de deshumidificación en las opciones 2 a 6 se han cuantificado para resolver estas cargas térmicas con una ocupación de 100 personas.

\subsection{Temperaturas operativas}

Una vez determinados de forma experimental y con suficiente aproximación los coeficientes de convección $h_{c}$ y de pérdidas por radiación $h_{r}$, y obtener los valores de pérdidas de calor sensible adecuados a la expresión [1], con unos buenos resultados de confort en la aplicación de los paneles de acondicionamiento térmico cerámico en sus diversas opciones, procedemos a comprobar los valores de la temperatura operativa de confort $T_{o}$ para el cuerpo humano (Tabla 6). Ésta podría definirse como «la temperatura uniforme de un recinto imaginario en el que el cuerpo intercambia el mismo calor seco (sin tener en cuenta las cargas latentes) por radiación y convección que en un mismo ambiente real» (22).

Tabla 4. Cálculo de temperaturas radiantes medias a través de los factores forma, según Fanger.

\begin{tabular}{|c|c|c|c|c|c|c|c|c|c|c|c|c|c|}
\hline & \multirow{2}{*}{$\mathbf{a}$} & \multirow{2}{*}{$\mathbf{b}$} & \multirow{2}{*}{ c } & \multirow{2}{*}{$\mathbf{a} / \mathbf{b}$} & \multirow{2}{*}{$\mathbf{b} / \mathbf{c}$} & \multirow{2}{*}{$\mathbf{F}$} & \multirow{2}{*}{$\mathbf{F x}$} & \multicolumn{2}{|c|}{ OP 1} & \multicolumn{2}{|c|}{$\begin{array}{c}\text { OP } 2 \\
\text { Pared plana }\end{array}$} & \multicolumn{2}{|c|}{$\begin{array}{c}\text { OP } 3 \\
\text { Techo plano }\end{array}$} \\
\hline & & & & & & & & $\begin{array}{c}\text { Tp } \\
\text { med }\end{array}$ & $\begin{array}{c}\text { Fx. Tp } \\
\text { med }\end{array}$ & $\begin{array}{c}\text { Tp } \\
\text { med }\end{array}$ & $\begin{array}{l}\text { Fx. Tp } \\
\text { med }\end{array}$ & $\begin{array}{c}\text { Tp } \\
\text { med }\end{array}$ & $\begin{array}{c}\text { Fx . Tp } \\
\text { med }\end{array}$ \\
\hline Suelo & 60 & 22,5 & 1,8 & 50 & 18,7 & 0,11 & 0,45 & 24 & 10,8 & 22,5 & 10,12 & 20,5 & 9,22 \\
\hline Techo & 60 & 22,5 & 7,8 & 7,7 & 2,88 & 0,105 & 0,4 & 25 & 10 & 24,5 & 9,8 & 17 & 6,8 \\
\hline Pared 1, 3 & 60 & 8,4 & 10,5 & 5,7 & 0,8 & 0,05 & 0,1 & 24 & 2,4 & 17 & 1,7 & 23,5 & 2,35 \\
\hline Pared 2, 4 & 22,5 & 8,4 & 30 & 0,75 & 0,28 & 0,018 & 0,036 & 24 & 0,86 & 23,5 & 0,84 & 24,2 & 0,87 \\
\hline Pared $1,3 \mathrm{~b}$ & 60 & 0,6 & 10,5 & 5,7 & 0,06 & 0,005 & 0,01 & 24 & 0,24 & 17 & 0,17 & 23,5 & 0,23 \\
\hline Pared 2, $4 \mathrm{~b}$ & 22,5 & 0,6 & 30 & 0,75 & 0,02 & 0,003 & 0,006 & 24 & 0,15 & 23,5 & 0,14 & 24,2 & 0,15 \\
\hline \multirow[t]{3}{*}{ Suma/Ta r med } & & & & & & & 1 & & 24,45 & & $\mathbf{2 2 , 7 7}$ & & 19,98 \\
\hline & \multirow{2}{*}{$\mathbf{a}$} & \multirow{2}{*}{$\mathbf{b}$} & \multirow{2}{*}{ c } & \multirow{2}{*}{$\mathbf{a} / \mathbf{b}$} & \multirow{2}{*}{$\mathbf{b} / \mathbf{c}$} & \multirow{2}{*}{$\mathbf{F}$} & \multirow{2}{*}{$\mathbf{F x}$} & \multicolumn{2}{|c|}{$\begin{array}{c}\text { OP } 4 \\
\text { Perpen pared }\end{array}$} & \multicolumn{2}{|c|}{$\begin{array}{c}\text { OP } 5 \\
\text { Techo bufle }\end{array}$} & \multicolumn{2}{|c|}{$\begin{array}{c}\text { OP } 6 \\
\text { Perpen total }\end{array}$} \\
\hline & & & & & & & & $\begin{array}{c}\text { Tp } \\
\text { med }\end{array}$ & $\begin{array}{c}\text { Fx. Tp } \\
\text { med }\end{array}$ & $\begin{array}{c}\text { Tp } \\
\text { med }\end{array}$ & $\begin{array}{l}\text { Fx. Tp } \\
\text { med }\end{array}$ & $\begin{array}{c}\text { Tp } \\
\text { med }\end{array}$ & $\begin{array}{c}\text { Fx. Tp } \\
\text { med }\end{array}$ \\
\hline Suelo & 60 & 22,5 & 1,8 & 50 & 18,7 & 0,11 & 0,45 & 22,5 & 10,02 & 20,5 & 9,22 & 22,5 & 10,02 \\
\hline Techo & 60 & 22,5 & 7,8 & 7,7 & 2,88 & 0,105 & 0,4 & 24,5 & 9,5 & 18,4 & 7,36 & 24,5 & 9,5 \\
\hline Pared 1, 3 & 60 & 8,4 & 10,5 & 5,7 & 0,8 & 0,05 & 0,1 & 21,5 & 2,1 & 23,5 & 2,4 & 17,4 & 1,74 \\
\hline Pared 2, 4 & 22,5 & 8,4 & 30 & 0,75 & 0,28 & 0,018 & 0,036 & 23,5 & 0,84 & 24,2 & 0,87 & 24,5 & 0,88 \\
\hline Pared 1, 3 b & 60 & 0,6 & 10,5 & 5,7 & 0,06 & 0,005 & 0,01 & 21,5 & 0,21 & 31,5 & 0,315 & 18,2 & 0,182 \\
\hline Pared 2, $4 \mathrm{~b}$ & 22,5 & 0,6 & 30 & 0,75 & 0,02 & 0,003 & 0,006 & 23,5 & 0,14 & 29,2 & 0,175 & 24,5 & 0,15 \\
\hline Suma/T ${ }^{a}$ r med & & & & & & & $\mathbf{1}$ & & 22,8 & & 20,34 & & $\mathbf{2 2 , 3 7}$ \\
\hline
\end{tabular}

Tabla 5. Cálculo de calor de cesión del individuo en régimen de verano.

\begin{tabular}{|c|c|c|c|c|c|c|c|c|c|}
\hline & $\boldsymbol{v}$ & $\boldsymbol{h}_{\mathrm{c}}$ & $T_{p}$ & $T_{a}$ & $\boldsymbol{h}_{\boldsymbol{r}}$ & $T_{r m}$ & $\boldsymbol{q}_{\text {cvi }}$ & $\boldsymbol{q}_{\text {rdi }}$ & TOTAL \\
\hline & & $h_{\mathrm{c}}=14,11 v^{0,24}$ & & & & & $q_{c v i}=h c(T p-T a)$ & $q_{r d i}=h r(T p-T r m)$ & $q_{c v i}+q_{r d i}$ \\
\hline & $\mathbf{m} / \mathbf{s}$ & $\mathbf{W} /{ }^{\circ} \mathbf{C}$ & ${ }^{\mathbf{O}} \mathrm{C}$ & ${ }^{\mathbf{O}} \mathbf{C}$ & $\mathrm{W} / \mathbf{m}^{\circ}{ }^{\circ} \mathbf{C}$ & ${ }^{\mathbf{O}} \mathbf{C}$ & $\mathbf{W}$ & $\mathbf{W}$ & $\mathbf{W}$ \\
\hline $\mathrm{OP}_{1}$ & 0,068 & 7,402 & 30,00 & 22,11 & 4,70 & 24,45 & 58,39 & 26,09 & 84,48 \\
\hline $\mathrm{OP} 2$ & 0,035 & 6,311 & 30,00 & 24,37 & 4,70 & 22,70 & 35,53 & 34,31 & 69,84 \\
\hline $\mathrm{OP}_{3}$ & 0,032 & 6,177 & 30,00 & 24,28 & 4,70 & 19,98 & 35,33 & 47,09 & 82,43 \\
\hline $\mathrm{OP}_{4}$ & 0,037 & 6,396 & 30,00 & 24,20 & 4,70 & 22,80 & 37,10 & 33,84 & 70,94 \\
\hline OP 5 & 0,039 & 6,477 & 30,00 & 24,10 & 4,70 & 20,34 & 38,22 & 45,40 & 83,62 \\
\hline OP 6 & 0,026 & 5,877 & 30,00 & 24,10 & 4,70 & 22,37 & 34,67 & 35,86 & 70,53 \\
\hline
\end{tabular}




$$
T_{o}=\frac{h_{r} T_{r m}+h_{c} T_{a}}{h_{r}+h_{c}}
$$

La interpretación de esta expresión resulta relevante para comprender la forma de trabajo de los sistemas de climatización por superficies radiantes. La sensación de confort del individuo en espacios cerrados, si consideramos a priori un control de la humedad relativa y la velocidad del aire en el marco que establece el RITE (entre un 40 y un 60\%, y o,15 a $0,24 \mathrm{~m} / \mathrm{s}$, respectivamente, según se trate de régimen de invierno o verano), depende tanto de la temperatura del aire que le envuelve como de la temperatura superficial de todos los paramentos que conforman el espacio. Y además en una proporción similar, o incluso un poco más relevante en lo que se refiere a la temperatura radiante media $T_{r m}$. Como se puede apreciar en el MUA la temperatura del aire interior es unos $2{ }^{\circ} \mathrm{C}$ superior en los sistemas radiantes frente al sistema convectivo.

En la Gráfica 1 se observan los valores de temperaturas en régimen de verano para el día 2 de agosto de 2015: temperatura del aire exterior, temperaturas del aire interior de los puntos 1 y 3 de la zona de ocupación, según se indican en la Figura 4, para el sistema convectivo actual u OP 1 y sistema de paneles radiantes en pared u OP 2 , y valores de temperatura interior del aire en el caso de que se desconectara el sistema de climatización. Igualmente se obtuvieron estos datos para todas las opciones, a través de la simulación calibrada antes descrita.

Como puede observarse en la Tabla 6, las temperaturas operativas se aproximan a los valores de $23{ }^{\circ} \mathrm{C}$ introducidos en las simulaciones realizadas a través de Design Builder para régimen de verano, como obliga el RITE. Al procurar un foco térmico de gran superficie en estos sistemas, en suelo, techo o pared, las temperaturas superficiales del foco emisor de calor o frío son más moderadas, consiguiendo la misma potencia de emisión que en los otros sistemas, y con similar temperatura operativa. Esta diferencia conlleva, como veremos, sustanciales ahorros energéticos y permite el uso de energías alternativas, como la solar o la geotermia.

\subsection{Evaluación comparativa de la demanda energética en verano e invierno}

Como última fase del análisis comparativo entre las 6 opciones se ha procedido a evaluar la demanda energética en régimen de verano y régimen de invierno. Para ello se ha utilizado la herramienta Design Builder, habiéndose calibrado a través de los resultados de monitorización, como se ha descrito anteriormente.

Para poder calibrar la simulación se obtuvieron por monitorización datos de temperaturas del aire, humedad relativa, temperatura superficial de los paramentos, etc. Algunos de los resultados se han mostrado en las Tablas 4 y 5 y en la Gráfica 1. A través de termografías se detectaron puentes térmicos, y se evaluaron posteriormente a través de la herramienta Antherm. Los resultados de factor de acoplamiento y valores de transmitancia térmica lineal se publicaron en 2014 y han sido utilizados para esta simulación (19). También se recogieron datos de temperatura del aire exterior y radiación solar mediante piranómetro ubicado en la cubierta a separación de $1 \mathrm{~m}$. Para establecer el valor de renovación del aire interior más infiltraciones de aire se procedió a ajustar los valores de consumos de energía eléctrica con los valores de consumos energéticos reales del edificio. Existe un único contador eléctrico para el conjunto. Una vez descontado el valor de consumos de iluminación, 2,8 kWh/ $\mathrm{m}^{2} \mathrm{a}$, se obtuvo el valor de los consumos energéticos anuales debidos a la climatización del edificio. El valor medio del periodo 2010-2014 es de 203.050 kWh/a. Se procedió a realizar simulaciones con sistema todo-aire de impulsión, determinando que el valor de volumen de aire de renovación real es de $2 \mathrm{ren} / \mathrm{h}$.

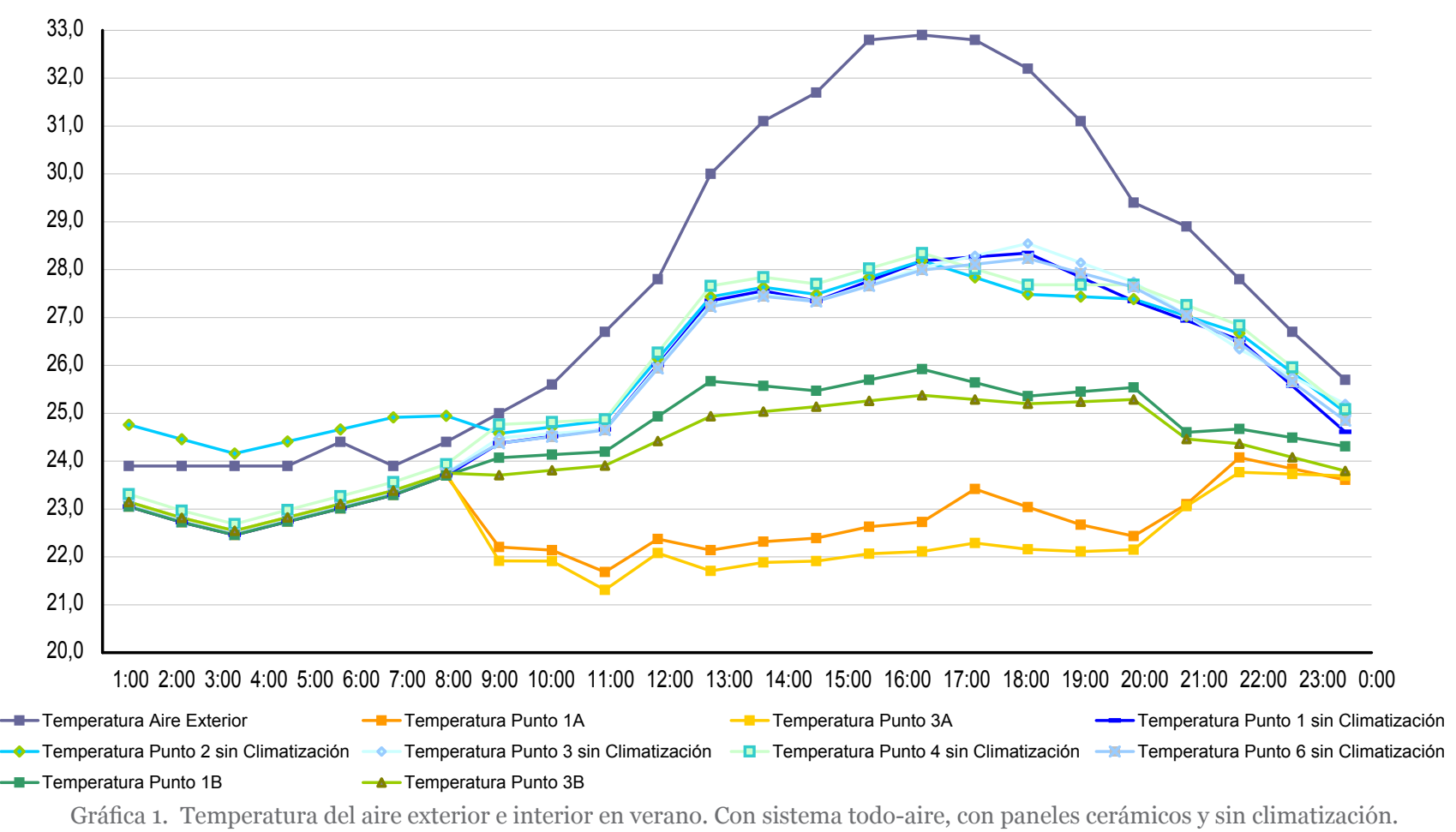


Tabla 6. Cálculo de temperaturas operativas para las 6 Opciones.

\begin{tabular}{|c|c|c|c|c|c|c|}
\hline & $\boldsymbol{v}$ & $h_{c}$ & $\boldsymbol{T}_{a}$ & $\boldsymbol{h}_{r}$ & $\boldsymbol{T}_{r m}$ & $T_{o}$ \\
\hline & & $h_{c}=14,11 v^{0,24}$ & & & & \\
\hline & $\mathbf{m} / \mathbf{s}$ & $\mathbf{W} /{ }^{\circ} \mathbf{C}$ & ${ }^{\mathbf{o}} \mathbf{C}$ & $\mathbf{W} / \mathbf{m}^{20} \mathbf{C}$ & ${ }^{\circ} \mathbf{C}$ & ${ }^{\mathbf{o}} \mathbf{C}$ \\
\hline $\mathrm{OP} 1$ & 0,068 & 7,402 & 22,11 & 4,70 & 24,45 & 23,02 \\
\hline $\mathrm{OP} 2$ & 0,035 & 6,311 & 24,37 & 4,70 & 22,70 & 23,66 \\
\hline $\mathrm{OP}_{3}$ & 0,032 & 6,177 & 24,28 & 4,70 & 19,98 & 22,42 \\
\hline $\mathrm{OP}_{4}$ & 0,037 & 6,396 & 24,20 & 4,70 & 22,80 & 23,61 \\
\hline OP 5 & 0,039 & 6,477 & 24,10 & 4,70 & 20,34 & 22,52 \\
\hline OP 6 & 0,026 & 5,877 & 24,10 & 4,70 & 22,37 & 23,33 \\
\hline
\end{tabular}

El escenario de climatización ha sido, pues, el siguiente: protección de paramentos de vidrio de la planta baja moderada mediante paneles DM. Lucernarios existentes cubiertos con lamas orientables. Ocupación de 100 personas en la sala de exposición. Iluminación de la sala de 300 lux. Renovación de aire $2 \mathrm{ren} / \mathrm{h}$. Infiltración de aire para solución constructiva poco estanca, equivalente a $0,7 \mathrm{ren} / \mathrm{h}$. En las Figuras 8, 9 y 10 se muestran las representaciones de esta simulación para el día 2 de agosto a las 16:0o h. Se muestra la sección transversal en el centro de la sala de exposiciones, para las opciones 1, 2 y 3, con temperaturas y velocidades del aire interior.

Los sistemas de acondicionamiento por superficies radiantes requieren deshumidificar el aire interior contrarrestando las cargas latentes, de forma que se consiga un adecuado confort térmico y no exista riesgo de condensaciones superficiales en los paneles cerámicos (5). La temperatura superficial de éstos debe ser superior a la temperatura de rocío, que con un $60 \%$ de humedad relativa se ha estimado de $16{ }^{\circ} \mathrm{C}$ según el ábaco sicométrico. Los resultados de la simulación en cuanto a consumos energéticos y porcentajes de comparativa frente a sistemas convectivos se muestran en la Tabla 7. La demanda energética es de $139,31 \mathrm{kWh} / \mathrm{m}^{2} \mathrm{a}$ para el sistema todo-aire actual, OP 1 , y $107,97 \mathrm{kWh} / \mathrm{m}^{2} \mathrm{a}$ para el sistema de paneles térmicos cerámicos en pared, OP 2, con un consiguiente ahorro energético del $22,5 \%$.

\section{CONCLUSIONES}

El gres porcelánico, por sus excelentes propiedades de resistencia mecánica, mínima absorción de agua y porosidad, y por sus altos coeficientes de conductividad térmica y efusividad, es excelente para la aplicación de acondicionamiento por superficies radiantes en los edificios. En el caso de piezas de gres porcelánico de gran formato y bajo espesor se pueden combinar con tramas capilares de tubos de polipropileno de diámetro aproximado $3 \mathrm{~mm}$, confeccionando paneles de acondicionamiento térmico cerámicos de hasta $3 \times 1 \mathrm{~m}$. Dichos paneles se pueden disponer de diversas formas tanto en pared como en techo, mediante trasdosados, o descolgados en techo tipo bafle, o a modo de costillas ortogonales en pared. También admiten la disposición de falsos techos modulares con acabado en cerámica.

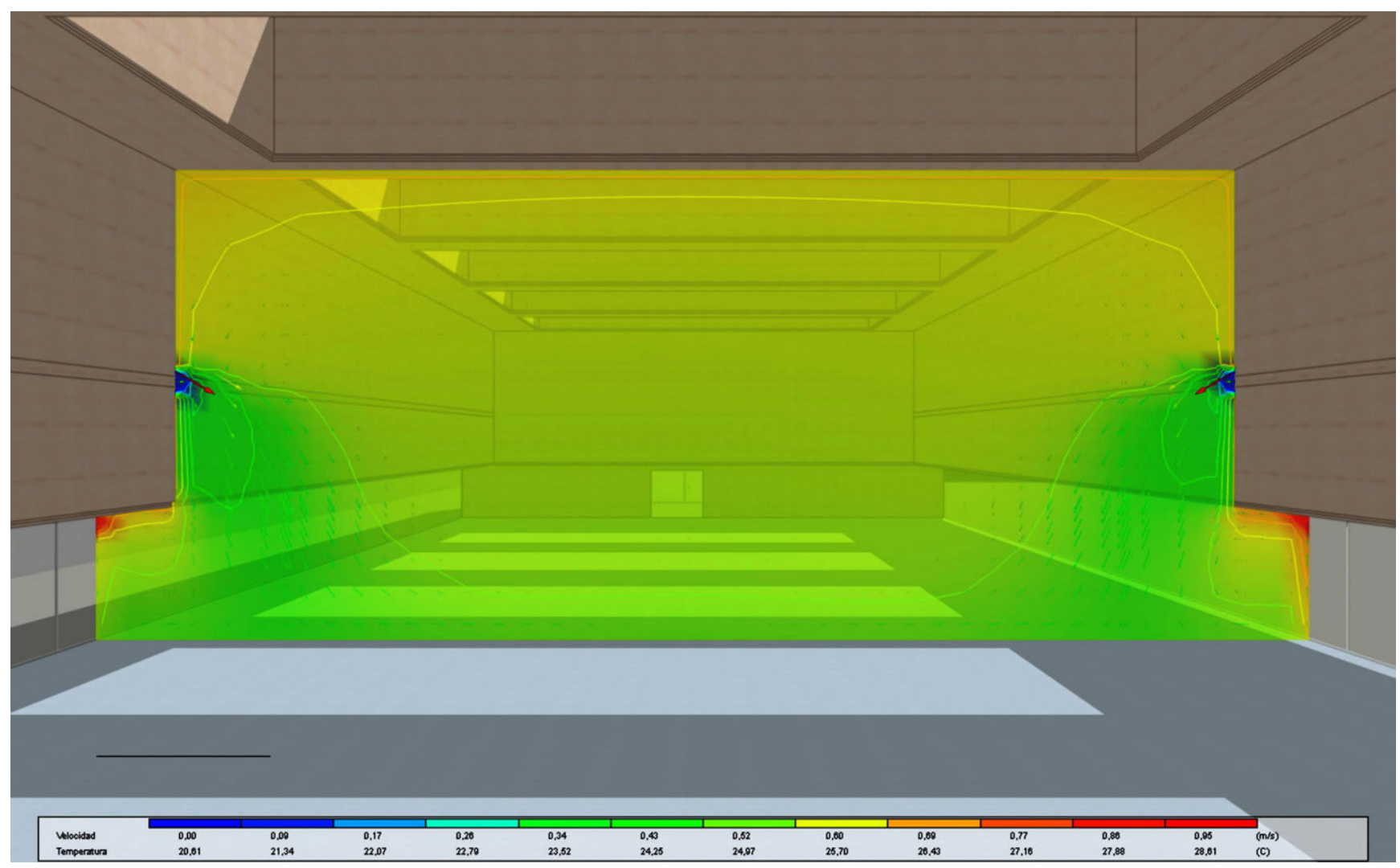

Figura 8. Simulación de temperaturas del aire con climatización de sistema convectivo todo-aire. OP 1. 


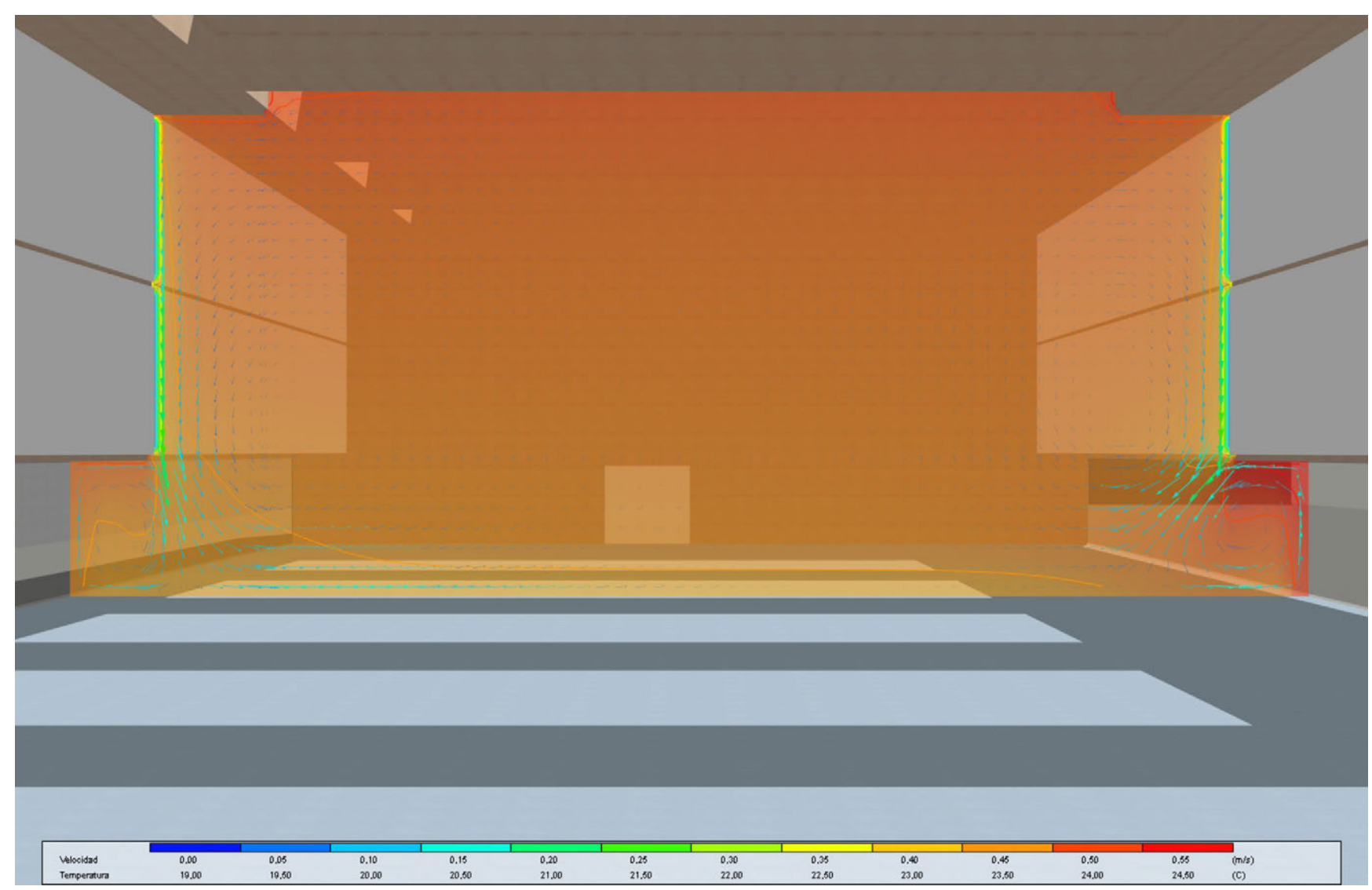

Figura 9. Simulación de $T_{a}$ y $v$ del aire con paneles térmicos cerámicos en pared. OP 2.

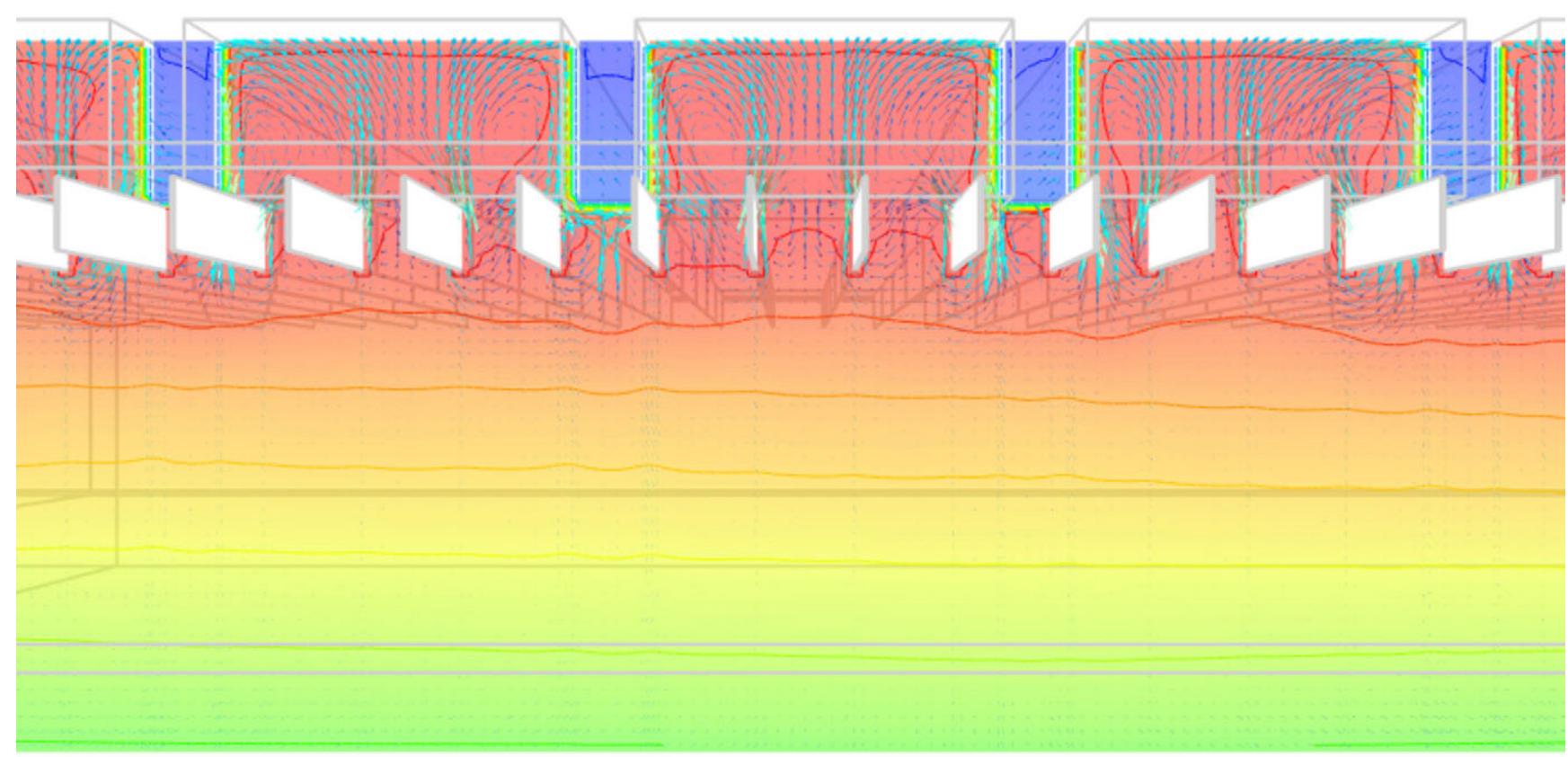

\begin{tabular}{|c|c|c|c|c|c|c|c|c|c|c|c|c|c|}
\hline & & & & & & & & & & & & & \\
\hline Velocidad & 0.00 & 0.05 & 0.09 & 0.10 & 0.15 & 0.20 & 0.25 & 0.30 & 0.35 & 0.40 & 0.46 & 0.50 & $(\mathrm{~m} / \mathrm{s})$ \\
\hline Temperatura & 15,00 & 16,00 & 16,82 & 17,00 & 18,00 & 19,00 & 20,00 & 21,00 & 22,00 & 23,00 & 24,00 & 25,00 & (C) \\
\hline
\end{tabular}

Figura 10. Simulación de $T_{a} \mathrm{y} v$ del aire con panel térmico cerámico colgado en techo, tipo bafle. OP 5 .

Se han patentado dichos paneles con interfaz de pasta conductora adhesiva, con excelentes resultados en su emisión térmica en régimen de verano e invierno. Se han realizado algunos prototipos que se han instalado en un despacho tipo del campus de la Universidad de Alicante, obteniéndose resultados de temperatura superficial de emisión de $17^{\circ} \mathrm{C}$ en menos de 10 minutos con distribución de agua fría a $15{ }^{\circ} \mathrm{C}$ en circuito secundario. 
Tabla 7. Cálculo de consumos energéticos anuales y comparativa frente a sistemas convectivos.

\begin{tabular}{|c|c|c|c|c|c|c|c|c|}
\hline & $\begin{array}{l}\text { VERANO de } 1 \text { de mayo a } 30 \text { noviembre } \\
\text { INVIERNO de } 1 \text { de diciembre a } 30 \text { abril } \\
\text { Ocupación } 100 \text { PERSONAS }\end{array}$ & & $\begin{array}{l}\text { OP } 1 \\
\text { Todo- } \\
\text { aire }\end{array}$ & $\begin{array}{c}\text { OP } 2 \\
\text { Paredes } \\
\text { KaRo }\end{array}$ & $\begin{array}{l}\text { OP 3 } \\
\text { Techo } \\
\text { panel } \\
\text { KaRo }\end{array}$ & $\begin{array}{l}\text { OP } 4 \\
\text { Paredes } \\
\text { costillas } \\
1 \text { KaRo }\end{array}$ & $\begin{array}{c}\text { OP } 5 \\
\text { Techo } \\
\text { bafle } \\
\text { KaRo }\end{array}$ & $\begin{array}{l}\text { OP 6 } \\
\text { Paredes } \\
\text { costillas } \\
2 \text { KaRo }\end{array}$ \\
\hline \multirow[t]{2}{*}{1} & Área efectiva & $\mathrm{m}^{2}$ & 1.417 & 1.417 & 1.417 & 1.417 & 1.417 & 1.417 \\
\hline & Área paneles cerámicos & $\mathrm{m}^{2}$ & & 672 & 660 & 672 & 570 & 840 \\
\hline 2 & Máxima carga térmica & $\mathrm{W} / \mathrm{m}^{2}$ & 80 & 75 & 70 & 75 & 75 & 77 \\
\hline 4 & Caudal mínimo de aire renovación & $\mathrm{m}^{3} / \mathrm{m}^{2} \mathrm{~h}$ & 3,05 & 3,05 & 3,05 & 3,05 & 3,05 & 3,05 \\
\hline 5 & Salto térmico del agua en verano & $\mathrm{k}$ & 6 & 3 & 4 & 3,5 & 5,6 & 3,2 \\
\hline 6 & Tiempo funcionamiento del sistema & h/año & 4.015 & 4.015 & 4.015 & 4.015 & 4.015 & 4.015 \\
\hline 7 & Tiempo funcionamiento bombas frío & h/año & 1.800 & 1.800 & 1.800 & 1.800 & 1.800 & 1.800 \\
\hline 8 & Total horas funcionamiento enfriamiento & h/año & 620 & 205 & 196 & 202 & 185 & 199 \\
\hline \multirow[t]{2}{*}{9} & Total horas funcionamiento calefacción & h/año & 310 & 140 & 136 & 138 & 126 & 135 \\
\hline & Ventilación & & & & & & & \\
\hline 10 & Caudal de aire impulsión & $\mathrm{m}^{3} / \mathrm{hm}^{2}$ & 29,41 & 3,05 & 3,05 & 3,05 & 3,05 & 3,05 \\
\hline 11 & Volumen de aire impulsión & $\mathrm{m}^{3} / \mathrm{h}$ & 41.674 & 4.320 & $4 \cdot 320$ & 4.320 & 4.320 & 4.320 \\
\hline 12 & Potencia ventilador & $\mathrm{kW}$ & 23,86 & 2,6 & 2,6 & 2,6 & 2,6 & 2,6 \\
\hline 13 & Volumen de aire retorno & $\mathrm{m}^{3} / \mathrm{h}$ & 39.407 & 3.024 & 3.024 & 3.024 & 3.024 & 3.024 \\
\hline \multirow[t]{2}{*}{14} & Potencia & $\mathrm{kW}$ & 11,27 & 1,2 & 1,2 & 1,2 & 1,2 & 1,2 \\
\hline & Ventiladores impulsión/retorno & & & & & & & \\
\hline 15 & Potencia ventilador & $\mathrm{kW}$ & 35,13 & 3,8 & 3,8 & 3,8 & 3,8 & 3,8 \\
\hline 16 & Consumo de potencia & MWh/año & 175,65 & 19,8 & 19,8 & 19,8 & 19,8 & 19,8 \\
\hline \multirow[t]{2}{*}{17} & Comparación & $\%$ & 100 & 11,2 & 11,2 & 11,2 & 11,2 & 11,2 \\
\hline & Bomba de frío & & & & & & & \\
\hline 18 & Caudal de agua & $\mathrm{l} / \mathrm{m}^{2} \mathrm{~h}$ & 11,46 & 21,5 & 15,05 & 18,92 & 11,51 & 20,15 \\
\hline 19 & Volumen de agua & l/h & $16.238,5$ & 30.465 & 21.325 & 26.809 & $16.320,8$ & 28.552 \\
\hline 20 & Potencia & & 2,5 & 4,7 & 3,15 & 4,19 & 2,56 & 4,47 \\
\hline 21 & Consumo de potencia & MWh/año & 4,05 & 7,52 & 5,04 & 6,71 & 4,09 & 7,15 \\
\hline \multirow[t]{2}{*}{22} & Comparación & $\%$ & 100 & 188 & 124 & 165,7 & 100,9 & 176,5 \\
\hline & Ventiladores y bombas & & & & & & & \\
\hline 23 & Potencia & $\mathrm{kW}$ & 37,63 & 8,5 & 6,95 & 7,99 & 6,36 & 8,27 \\
\hline 24 & Consumo de potencia & MWh/año & 179,7 & 27,32 & 24,84 & 26,51 & 23,89 & 26,95 \\
\hline \multirow[t]{2}{*}{25} & Comparación & $\%$ & 100 & 15,2 & 13,82 & 14,7 & 13,29 & 14,9 \\
\hline & Deshumidificadores fan-coils & & & & & & & \\
\hline 26 & Potencia & $\mathrm{kW}$ & & 18,66 & 18,66 & 18,66 & 18,66 & 18,66 \\
\hline \multirow[t]{2}{*}{27} & Consumo de potencia & MWh/año & & 50,39 & 50,39 & 50,39 & 50,39 & 50,39 \\
\hline & Sistema de refrigeración & & & & & & & \\
\hline 28 & Demanda de potencia & & 0,3 & 0,25 & 0,26 & 0,25 & 0,27 & 0,25 \\
\hline 29 & Potencia de emisión & $\mathrm{W} / \mathrm{m}^{2}$ & 85 & 69 & 75 & 70 & 91 & 72 \\
\hline 30 & Potencia & $\mathrm{kW}$ & 113,36 & 82,02 & 85,13 & 83,21 & 88,86 & 86,70 \\
\hline 31 & Consumo de potencia verano & MWh/año & 116,49 & 44,46 & 50,36 & 45,33 & 52,77 & 47,25 \\
\hline \multirow[t]{2}{*}{32} & Comparación & $\%$ & 100 & 38,2 & 43,2 & 38,9 & 45,3 & 40,6 \\
\hline & Sistema de calefacción & & & & & & & \\
\hline 34 & Potencia & $\mathrm{kW}$ & 91,8 & 85,0 & 92,6 & 87,8 & 102,7 & 89,1 \\
\hline 35 & Consumo de potencia invierno & MWh/año & 80,99 & 30,88 & 32,2 & 31,92 & 39,81 & 32,12 \\
\hline 36 & Consumo de energía al año & MWh/año & 197,48 & 153,05 & 157,79 & 154,15 & 166,87 & 156,71 \\
\hline 37 & Comparación & $\%$ & 100 & 77,5 & 79,9 & 78,1 & 84,5 & 79,3 \\
\hline
\end{tabular}

La aplicación de los paneles de acondicionamiento térmico cerámico ATC conlleva importantes ahorros energéticos. En el caso analizado del Museo de la Universidad de Alicante éstos estarían entre un 15 y un $22 \%$ respecto a los sistemas convectivos todo-aire que existen en la actualidad. Los factores más determinantes son la reducción de energía para la distribución de agua frente al aire de impulsión, con reducciones de un 70 a un $80 \%$, y la reducción de cargas térmicas al estar la temperatura del aire interior en torno a $2{ }^{\circ} \mathrm{C}$ por encima de la que existe en los sistemas convectivos. Estos ahorros energéticos podrían incrementarse sustancialmente con el uso de energías alternativas, como la solar y la geotermia, y sistemas de absorción y por cloruro de litio o energía química, al trabajar con temperaturas del agua más moderadas en la distribución. 
La disposición de paneles trasdosados en pared, tanto en disposición plana como ortogonal al paramento, produce menores niveles de cesión del calor del usuario frente a sistemas convectivos y sistemas radiantes por techo y tipo bafle, produciendo niveles de confort algo inferiores. La disposición de los paneles descolgados del techo o tipo bafle aumentan la convección del aire, aumentando hasta un $10 \%$ la potencia de emisión y la cesión de calor del individuo en verano, mejorando la sensación de confort, aunque aumentando un $9 \%$ el consumo energético frente a trasdosados de techo o de pared.

\section{REFERENCIAS}

(1) ASCER. (2003). Guía de la baldosa cerámica. Castellón, Generalitat Valenciana: COACV, Instituto Valenciano de la Edificación.

(2) Ruá, M.J., Vives, L., Civera, V., López-Mesa, B. (2010, 15 de febrero). Aproximación al cálculo de la eficiencia energética de fachadas ventiladas y su impacto ambiental. En Proc. of XI Congreso Mundial de la Calidad del Azulejo y del Pavimento QUALICER 1O, Castellón.

(3) Cantabella, V., et al. (2010, 15 de febrero). Dinamycs of the Thermal Performance of an Electric Radiant Floor with Removable Ceramic Tiles. En Proc. of XI Congreso Mundial de la Calidad del Azulejo y del Pavimento QUALICER 1O, Castellón.

(4) Stetiu, C., Lawrence Berkeley Nacional Laboratory. (1992). Energy and peak power savings potential of radiant cooling systems in US commercial buildings. Energy and Buildings, 30(2): 127-138.

(5) Dynamobel. Manual de climatización tranquila. Tramas Karo. http://www.dynamobel.com/Productos/descargas/ INSTALACIONES/CLIMATIZACION/manual\%20tecnico\%20climatizacion.pdf.

(6) Echarri, V., Sánchez, R. (2016). Climatización por superficies radiantes mediante tramas capilares. En Hernández, R., et al. (eds.) Architectura Eco-eficiente, Tomo II. San Sebastián: Servicio Editorial de la Universidad del País Vasco.

(7) Climate Well 10, V9:3. Reference Material for User \& Installation Manuals. http://www.climatewell.com.

(8) Monné, C., Alonso, S., Palacín, F. (2011). Evaluación de una instalación de refrigeración por absorción con energía solar. Información Tecnológica, 22(3): 39-41.

(9) Zamora, M. (2008). Empleo de bombas de calor acopladas a intercambiadores geotérmicos: Proyecto Geocool. Montajes e Instalaciones. Revista técnica sobre la construcción e ingeniería de las instalaciones, 38(426): 66-72.

(10) Haiwen, S., Lin, D., Xiangli, L. (2010). Quasi-dynamic energy-saving judgment of electric-driven seawater source heat pump district heating system over boiler house district heating system. Energy and Buildings, 42(12): 2424-2430.

(11) Li, Z., Songtao, H. (2006). Research on the heat pump system using seawater as heat source or sink. Building Energy \& Environment 25(3): 34-38.

(12) Echarri, V., González, A.B., Pérez, M.I. (2012, 13 de febrero). Refreshing Architectural Spaces by Means of Large-Sized Vertical Ceramic Panels. En Proc. of XII Congreso Mundial de la Calidad del Azulejo y del Pavimento QUALICER 12, Castellón.

(13) Patente de $\mathrm{n}^{0}$ solicitud P201001626. Panel de Acondicionamiento Térmico Cerámico. Víctor Echarri (UA), Elena Oviedo (ASCER) y Vicente Lázaro (ITC).

(14) Zanelli, C., et al. (2010, 15 de febrero). Porcelain Stonware large Slabs Processing and Technological Properties. En Proc. of XI Congreso Mundial de la Calidad del Azulejo y del Pavimento QUALICER 1O, Castellón.

(15) Beka. (2000). Technical information Go. Berlín: Beka Heiz-undKülmatten.

(16) Knight, E. (2009). Xaar: innovative inkjet technology for the ceramic tile industry. En Digital decoration of ceramic tiles, pp. 70-73. Italia: ACIMAC.

(17) Hutchings, I. (2010, 15 de febrero). Ink-jet Printing for the Decoration of Ceramic Tiles: Technology and opportunities. En Proc. of XI Congreso Mundial de la Calidad del Azulejo y del Pavimento QUALICER 1O, Castellón.

(18) Echarri, V., Salvador, M., Ramírez, G., Espinosa, A. (2012, 15 de febrero). Lesiones en Paneles Fenólicos de Madera Baquelizada: Diagnóstico e Intervención. En Proc. of $4 .^{\circ}$ Congreso de Patología y Rehabilitación de Edificios (PATORREB). Santiago de Compostela: Ed. Colegio Oficial de Arquitectos de Galicia, P2-o6.

(19) Echarri, V., Galiano, A., Pérez, M.I., González, A.B. (2014). Conditioning systems by radiant surfaces: comparative analysis of thermal ceramic panels versus the conventional systems in a museum. WIT Transactions on Engineering Sciences, 83 .

(20) Fanger, O.P. (1970). Thermal Comfort.Analysis and Applications in Environmental Engineering. New York: McGrawHill Book Company.

(21) Ortega, M., Ortega A. (2001). Calefacción y refrescamiento por superficies radiantes. Madrid: Paraninfo, Thomson Learning.

(22) American Society of Heating, Refrigeration and Air Condiotioning Engineers. (2010). Handbook of Fundamentals. Atlanta: ASHRAE.

(23) Sala Lizarraga, J.M. (2012). Transmisión de calor en edificios. En Hernández, R., et al. (eds.), Arquitectura Ecoeficiente, volumen I, capítulo 2. San Sebastián: Servicio Editorial de la UPV/EHU.

(24) Mosteller, R.D. (1987). Simplified calculation of body-surface area. The New England Journal of Medicine, 317(17): 1098. 